\title{
Novos táxons de Cerambycidae (Coleoptera) das Américas Central e do Sul
}

\author{
Ubirajara R. Martins ${ }^{1,3} \&$ Maria Helena M. Galileo ${ }^{2,3}$ \\ 1. Museu de Zoologia, Universidade de São Paulo, Caixa Postal 42594, 04218-970, São Paulo, SP, Brasil. (urmsouza@usp.br) \\ 2. Museu de Ciências Naturais, Fundação Zoobotânica do Rio Grande do Sul. Rua Dr. Salvador França, 1427, 90690-000, Porto Alegre, RS, Brasil. (galileo@fzb.rs.gov.br) \\ 3. Pesquisador do CNPq.
}

\begin{abstract}
New taxa of Cerambycidae (Coleoptera) from Central and South America. New taxa described: in Cerambycinae, Bomarion caudatum sp. nov., from Bolivia (Ectenessini); Nephalius levigatus sp. nov., from Brazil, Paraíba (Elaphidiini); Bothriospila pulcherrima sp. nov., from Brazil, Bahia (Bothriospilini); Cycnidolon rufescens sp. nov., from Brazil, Paraíba (Neoibidionini). In Lamiinae: Cicatricallia gen. nov., type species: C. cicatricosa sp. nov. from Trindad and Tobago (Calliini); Mimasyngenes clarkei sp. nov., from Trinidad and Tobago and Mimasyngenes fonticulus sp. nov., from Brazil, Piauí; Ibypeba gen. nov., type species: I. camiri sp. nov., from Bolivia; Micratelodesmis gen. nov., type species: M. minor sp. nov. (Desmiphorini); Lycidola affinis sp. nov. from Trinidad and Tobago (Hemilophini). New records: Lycidola beltii Bates, 1872 from Costa Rica and Alampyris fuscus Martins \& Galileo, 2008 from Panamá (Hemilophini).
\end{abstract}

KEYWORDS. Cerambycinae, Lamiinae, new genera, new records, new species.

RESUMO. Novos táxons descritos: em Cerambycinae, Bomarion caudatum sp. nov., da Bolívia (Ectenessini); Nephalius levigatus sp. nov., do Brasil, Paraíba (Elaphidiini); Bothriospila pulcherrima sp. nov., do Brasil, Bahia (Bothriospilini); Cycnidolon rufescens sp. nov., do Brasil, Paraíba (Neoibidionini). Em Lamiinae: Cicatricallia gen. nov., espécie-tipo: C. cicatricosa sp. nov. de Trindade e Tobago (Calliini); Mimasyngenes clarkei sp. nov., de Trinidad e Tobago e Mimasyngenes fonticulus sp. nov., do Brasil, Piauí; Ibypeba gen. nov., espécie-tipo: I. camiri sp. nov., da Bolívia; Micratelodesmis gen. nov., espécie-tipo: M. minor sp. nov. (Desmiphorini); Lycidola affinis sp. nov. de Trinidad e Tobago (Hemilophini). Novos registros: Lycidola beltii Bates, 1872 para a Costa Rica e Alampyris fuscus Martins \& Galileo, 2008 para o Panamá (Hemilophini).

PALAVRAS-CHAVE. Cerambycinae, Lamiinae, novas espécies, novos gêneros, novos registros.

Material recebido de diversas instituições nos facultou o reconhecimento de novos táxons em quatro tribos de Cerambycinae e em três de Lamiinae. Em Cerambycinae são descritas espécies novas em Ectenessini, Elaphidionini, Bothriospilini e Neoibidionini. Em Lamiinae são propostos dois novos gêneros em Desmiphorini, além de espécies inéditas em Mimasyngenes Breuning, 1950; um gênero novo, monotípico, em Calliini; uma nova espécie em Hemilophini e apresentamos novos registros para duas espécies.

Siglas das instituições mencionadas no texto: ACMS, American Coleoptera Museum, San Antonio, EUA; MNKM, Museu Noel Kempff Mercado, Santa Cruz, Bolívia; MZSP, Museu de Zoologia, Universidade de São Paulo, São Paulo, Brasil; USNM, National Museum of Natural History, Washington, EUA; UEFS, Universidade Estadual Feira de Santana, Bahia, Brasil.

\section{CERAMBYCINAE ECTENESSINI}

\section{Bomarion caudatum sp. nov.}

(Fig. 1)

Etimologia. Latim, cauda = cauda; alusivo à coloração do ápice dos élitros.

Cabeça com tegumento castanho-avermelhado. Fronte com pontos esparsos (32x). Vértice com os pontos mais concentrados no occipício. Lobos oculares superiores com 3(4) fileiras de omatídios. Último artículo dos palpos maxilares normalmente expandido. Antenas avermelhadas na base e gradualmente mais amareladas para o ápice. Escapo subcilíndrico, pontuado, sem asperezas. Antenômero III carenado.

Protórax mais longo do que largo com constrição basal apenas mais acentuada que a anterior. Áreas laterais do protórax pontuadas. Pronoto glabro, pontuado, exceto numa área suboval, centro-basal lisa, que se estende da base até pouco antes do meio. Centro do mesosterno levemente aprofundado.

Élitros amarelados nos 3/4 basais (a declividade basal avermelhada em pequena extensão) e o quarto apical preto; a área preta projeta-se para frente junto da sutura; região umeral com mancha avermelhada. Extremidades elitrais emarginadas com curtas projeções nos ângulos externo e interno.

Fêmures avermelhados com as extremidades ligeiramente mais claras. Tíbias e tarsos alaranjados. Face ventral amarelada.

Dimensões, em mm, holótipo macho. Comprimento total, 8,7; comprimento do protórax, 1,8; maior largura do protórax, 1,3; comprimento do élitro, 6,3; largura umeral, 1,9.

Material-tipo. Holótipo macho, BOLÍVIA, Santa Cruz: Florida (4 km N Bermejo, Refugio los Volcanes, $18^{\circ} 06^{\prime} \mathrm{S}, 63^{\circ} 36^{\prime} \mathrm{W}$, 1000-1200 m), 25-29.X.2011, Wappes \& Skillman col. (MNKM).

Discussão. Bomarion caudatum sp. nov. tem padrão de colorido elitral peculiar. A única espécie do gênero com padrão de colorido elitral mais semelhante é B. achrostum Napp \& Martins, 1982, descrita do Peru, mas tem élitros unicolores. Além disso, os fêmures em B. achrostum são pretos. 
Bomarion amborense Galileo \& Martins 2008 também foi descrita da Bolívia, mas possui padrão de colorido elitral diferente, antenas e fêmures amarelados e antenômero III sem carena.

\section{ELAPHIDIINI}

\section{Nephalius levigatus sp. nov.}

(Fig. 2)

Etimologia. Latim, levigatus $=$ liso; alusivo à escassa pubescência corporal.

Cabeça castanho-avermelhada. Fronte e vértice sem pubescência, com pontos densos. Lobos oculares superiores estreitos, com cinco fileiras de omatídios. Antenas amareladas atingem o ápice dos élitros, aproximadamente, na ponta do antenômero VIII. Escapo gradualmente engrossado para o ápice, sem pontos ásperos, com sulco raso na base. Antenômeros III-V com espinho apical interno.

Protórax castanho-avermelhado, aspecto brilhante, com pubescência muito esparsa. Pronoto com cinco tubérculos: um central, alongado, dois ântero-laterais, arredondados no topo e com prolongamento em direção aos dois látero-basais; entre as elevações, pontos moderadamente densos. Áreas laterais do protórax microesculturadas, com pontos esparsos. Prosterno revestido por pilosidade esbranquiçada, entremeada por pontos esparsos, profundos. Escutelo com pubescência serícea, esbranquiçada.

Élitros castanho-amarelados, com pubescência pruinosa, esparsa, sem pontos contrastantes na metade apical. Ápices elitrais de per si acuminados, com espinho projetado, agudo e preto.

Fêmures pedunculados, clavados, alaranjados; meso- e metafêmures com a região apical preta. Metatíbias carenadas. Metatarsômero I com comprimento igual ao do II+III.

Esternos torácicos e urosternitos avermelhados, com pubescência fina e esparsa.

Dimensões, em mm, holótipo fêmea. Comprimento total, 16,8; comprimento do protórax, 3,0; maior largura do protórax, 3,4; comprimento do élitro, 12,3; largura umeral, 4,0 .

Material-tipo. Holótipo macho, BRASIL, Paraíba: Areia (Brejo Paraibano, Pau Ferro, 3544'50,7'W 0658'21,2”S, $567 \mathrm{~m}$ ), 25-29.IX.2011, A. M. Silva Neto \& F. E. Nascimento col., armadilha luminosa (UEFS).

Discussão. Nephalius Newman 1841 foi revalidado por Martins (2005) e continha duas espécies: $N$. cassus Newman 1841 e N. spiniger (Blanchard, 1841). Nephalius levigatus sp. nov. apresenta pronoto brilhante e pontuado no intervalo entre os tubérculos; em $N$. cassus e $N$. spiniger, o pronoto é provido de pubescência abundante $\mathrm{e}$ os pontos não são visíveis. Em $N$. levigatus, a pubescência pruinosa dos élitros é muito esparsa e pouco visível e, nas duas outras espécies, é bem evidente.

\section{BOTHRIOSPILINI}

\section{Bothriospila pulcherrima sp. nov.}

(Fig. 3)

Etimologia. Latim, pulcherrima $=$ belíssima.

Cabeça com tegumento preto. Fronte revestida por pilosidade amarelada e entre os tubérculos anteníferos sulco longitudinal profundo prolongado até entre os lobos oculares superiores. Vértice coberto por pilosidade amarelada, com tubérculo centro-longitudinal desnudo e brilhante. Lobos oculares superiores com oito fileiras de omatídios. Genas aguçadas. Antenas atingem o ápice elitral, aproximadamente, no meio do antenômero X. Escapo com tegumento preto, menos longitudinalmente na margem anterior, com tegumento avermelhado; superfície densamente pontuada, com pilosidade amarelada mais longa no lado interno. Flagelômeros com tegumento preto, cobertos por pilosidade amarelada; nos basais com franja compacta e curta.

Protórax castanho-avermelhado e elevações com tegumento preto, revestido por pilosidade amarelada. Pronoto com uma linha longitudinal elevada, no meio, ligeiramente sinuosa e estreita que não alcança a borda anterior nem a posterior; de cada lado, uma faixa de tegumento mais escuro, com irregularidades e tubérculo glabro, muito pequeno, no nível do meio. Entre essa faixa e o espinho lateral a superfície pronotal é muito irregular e provida de tubérculos com ápice glabro. Áreas laterais do protórax com espinho no meio e gibosidade entre o espinho e a borda anterior do protórax. Prosterno com depressão transversal no meio. Processo prosternal com tubérculo e truncado posteriormente. Escutelo preto coberto por pilosidade amarelada.

Élitros com tegumento castanho-amarelado e revestido por pilosidade amarelada; cada um com três manchas dorsais, elípticas, róseas com bordas brancas e elevadas: uma contígua à base, outra no meio e uma terceira no terço apical. Extremidades elitrais truncadas e com dois espinhos pretos, o externo pouco mais longo que o sutural.

Fêmures sublineares, amarelados com as faces dorsal e ventral estreitamente acastanhadas; ápices dos meso- e metafêmures com espinho longo e preto. Tíbias amareladas com faixa acastanhada, estreita e pouco notável, no lado interno.

Face ventral do corpo com tegumento amarelado coberto por pilosidade amarelada. Último urosternito transversal com pelos rijos, clavados e curvos na margem ventral.

Dimensões, em mm, holótipo fêmea. Comprimento total, 33,1; comprimento do protórax, 5,2; maior largura do protórax, 8,9; comprimento do élitro, 25,1; largura umeral, 9,8 .

Material-tipo. Holótipo fêmea, BRASIL, Bahia: Maracás, 2526.III.2012, sem nome do coletor, armadilha luminosa (UEFS). 
Discussão. Bothriospila pulcherrima sp. nov. distingue-se de B. elegans Aurivillius, 1923, pelos flagelômeros com tegumento preto; pelo espinho lateral do protórax situado no meio; pelas manchas elitrais arredondadas; pela ausência de carena umeral; pelo desenvolvimento do espinho sutural do ápice dos élitros. Em B. elegans: flagelômeros com tegumento amarelado; espinho lateral do protórax situado no terço basal; manchas elitrais alongadas, a central com entalhe no lado ântero-externo; carena umeral presente; espinho sutural do ápice dos élitros sensivelmente mais curto que o externo.

\section{NEOIBIDIONINI}

\section{Cycnidolon rufescens sp. nov.}

(Fig. 4)

Etimologia. Latim, rufescens $=$ avermelhado; alusivo ao colorido geral.

Cabeça castanho-avermelhada, com pubescência serícea amarelada. Olhos divididos. Lobos oculares superiores com três fileiras de omatídios. Antenas castanho-avermelhadas. Antenômero III, nos machos, pedunculado e clavado, pedúnculo não carenado, com aproximadamente um quinto do comprimento total.

Protórax castanho-avermelhado com pubescência serícea esparsa. Pronoto com três tubérculos: o central mais evidente e os ântero-laterais, apenas indicados.

Élitros castanho-avermelhados, sem manchas claras na metade anterior, com pubescência mais evidente no limite entre as metades anterior (mais brilhante) e posterior. Extremidades elitrais com espinho no lado externo, não contrastante com o colorido do restante do tegumento.

Fêmures alaranjados com os ápices escuros. Extremidades dos meso- e metafêmures com abas apicais aguçadas.

Face ventral do corpo avermelhada, com pubescência esbranquiçada.

Dimensões, em mm, holótipo macho/parátipo fêmea. Comprimento total, 8,9/9,6; comprimento do protórax, 2,1/2,2; maior largura do protórax, 1,4/1,4; comprimento do élitro, 5,6/6,5; largura umeral, 2,0/1,9.

Material-tipo. Holótipo macho, BRASIL, Paraíba: Areia (Brejo Paraibano, Pau Ferro, 3544'50,7'W 0658'21,2'S, $567 \mathrm{~m}$ ), 25-29.IX.2011, A. M. Silva Neto \& F. E. Nascimento col., armadilha luminosa (UEFS). Parátipo fêmea, mesmos dados do holótipo (MZSP).

Discussão. Segundo a chave para espécies de Cycnidolon (Martins \& Galileo, 2007), apenas C. immaculatum Galileo \& Martins, 2004, da Bolívia, apresenta olhos divididos e antenômero III engrossado nos machos. Cycnidolon rufescens sp. nov. também apresenta estas características e difere de $C$. immaculatum pelo colorido geral castanho-avermelhado, pelo antenômero III dos machos com pedúnculo mais curto e sem carena; pelos tubérculos pronotais apenas indicados; pela pubescência serícea da metade apical dos élitros menos evidente e pelos espinhos apicais da mesma cor que a da metade posterior dos élitros. Em C. immaculatum, o colorido geral é castanho-escuro, o antenômero III dos machos tem pedúnculo mais longo e carenado, os tubérculos do pronoto são mais evidentes, a pubescência da metade apical dos élitros é evidente e os espinhos são amarelados e bem contrastantes com o colorido da metade apical.

\section{LAMIINAE CALLIINI}

\section{Cicatricallia gen. nov.}

Espécie-tipo. Cicatricallia cicatricosa sp. nov.

Etimologia. Latim, cicatrix = cicatriz; alusivo à cicatriz do escapo.

Fronte losangular, com os lados divergentes para a parte inferior. Olhos com granulação moderada. Lobos oculares superiores tão distantes entre si quanto o dobro da largura de um lobo. Escapo subcilíndrico, com cicatriz. Flagelômeros lineares. Antenômero III apenas mais curto que o IV.

Protórax mais largo que longo, com espinho lateral de comprimento moderado, situado atrás do meio. Pronoto regularmente convexo, com pelos relativamente longos. Processo prosternal laminiforme. Processo mesosternal sem tubérculo.

Élitros sem crista centro-basal, com pelos de comprimento moderado em toda a superfície. Extremidades elitrais arredondadas

Fêmures fusiformes; face ventral dos meso- e metafêmures com área levemente côncava, glabra, brilhante para encaixe das meso- e metatíbias. Mesotíbias sem sulco. Metatarsômero I tão longo quanto o comprimento do II+III.

Discussão. Três gêneros de Calliini apresentam cicatriz no escapo além de protórax com espinho lateral e processo mesosternal sem tubérculo: Mimolaia Bates 1885, Ardeосотиs Galileo \& Martins, 1988 e Graminea Thomson, 1864. Cicatricallia gen. nov. difere de Mimolaia pelo aspecto geral mais compacto, pelos fêmures com áreas ventrais deprimidas, pela pubescência grosseira no pronoto e nos élitros. Em Mimolaia, o aspecto geral é mais esbelto, os fêmures não têm áreas deprimidas na face ventral e a pubescência protórax e elitral é fina e decumbente. Além disso, várias espécies de Mimolaia têm antenas com artículos brancos.

Difere de Ardeocomus por não apresentar manchas de pubescência no pronoto; pelas extremidades dos élitros arredondadas e pelos fêmures com áreas ventrais deprimidas. Em Ardeocomus, o pronoto e os élitros têm áreas cobertas por pubescência esbranquiçada, os ápices elitrais são truncados com espículo externo e os fêmures não têm áreas deprimidas na face ventral. 
Difere de Graminea pelo aspecto geral compacto, pelo antenômero III apenas mais curto que o IV e pela área deprimida dos metafêmures, que ocupa quase integralmente a face ventral. Em Graminea, $\mathrm{o}$ antenômero III é mais longo do que o IV e a área deprimida da face ventral dos fêmures ocupa apenas o quarto apical.

\section{Cicatricallia cicatricosa sp. nov.}

(Fig. 5)

Colorido geral castanho-escuro; tegumento corporal brilhante e, conforme a incidência da luz, com aspecto dourado, especialmente no pronoto e no dorso dos élitros. Antenas pretas. Prosterno, mesosterno, coxas e bases dos fêmures com tegumento avermelhado. Cabeça revestida por pubescência branca e brilhante. Escapo com pubescência branca. Antenômeros V-XI com comprimentos subiguais.

Pronoto esparsa e finamente pontuado com pubescência branca, esparsa e convergente para o meio. Élitros quase sem pubescência no sexto basal; a partir do terço anterior com pubescência branca, relativamente longa e não nitidamente organizada em fileiras, estas mais evidentes nos lados (cabeça do inseto voltada para a fonte luminosa).

Tíbias avermelhadas nas bases e pretas no restante. Face ventral do corpo coberta por pilosidade relativamente longa e mais esparsa no meio do metasterno e dos urosternitos.

Dimensões, em mm, holótipo macho. Comprimento total, 5,0; comprimento do protórax, 1,1; maior largura do protórax, 1,6; comprimento do élitro, 4,0; largura umeral, 1,8. Comprimento dos antenômeros: III, 0,7; IV, 0,8.

Material-tipo. Holótipo macho, BOLÍVIA, Santa Cruz: Potrerillo del Genda (Snake Farm, $17^{\circ} 40^{\prime} \mathrm{S}, 63^{\circ} 27^{\prime} \mathrm{W}, 370-400 \mathrm{~m}$ ), 22.X.2011, Skillman \& Wappes col. (MNKM).

\section{DESMIPHORINI}

\section{Mimasyngenes clarkei sp. nov.}

(Fig. 6)

Etimologia. O nome específico é uma homenagem a Robin O. S. Clarke, autor da revisão do gênero Mimasyngenes.

Tegumento castanho-avermelhado. Setas pretas em todas as regiões corporais, menos nos tarsos e na face ventral. Cabeça revestida por pubescência esbranquiçada e densa. Lobos oculares superiores desenvolvidos, largos, tão distantes entre si quanto aproximadamente a largura de um lobo. Antenas castanho-avermelhadas, quebradas na ponta do antenômero IX, cujo ápice atinge, aproximadamente, o sexto apical dos élitros. Escapo (40x) com pubescência esbranquiçada e esparsa e pelos longos em toda a superfície. Antenômero III com comprimento subigual ao IV, antenômeros V-IX com comprimentos subiguais.
Protórax apenas mais largo que longo. Lados do protórax com espinho longo, evidente, acuminado, com ápice voltado para trás. Pronoto $(40 \mathrm{x})$ densamente pontuado e com pubescência esbranquiçada moderadamente densa.

Élitros densamente pontuados em toda superfície; os pontos são menos profundos em direção ao ápice com exceção nas regiões circum-escutelares, onde os pontos organizam-se em linhas longitudinais. Extremidades elitrais ligeiramente aguçadas e desarmadas.

Pernas castanho-avermelhadas. Face ventral do corpo revestida por pubescência esbranquiçada; lados do metasterno e dos urosternitos pontuados. Urosternito $\mathrm{V}$ intumescido com entalhe apical discreto em forma de meia-lua.

Dimensões, em mm, holótipo fêmea. Comprimento total, 6,6; comprimento do protórax, 1,2; maior largura do protórax, 1,3; comprimento do élitro, 4,0; largura umeral, 1,7. Comprimento dos antenômeros: III, 0,7; IV, 0,7.

Material-tipo. Holótipo fêmea, TRINIDAD E TOBAGO, Trinidad: Curepe (Santa Margarita Circular road), 28.VI.1972, F. D. Bennett col., "blacklight trap" (ACMS).

Discussão. Por apresentar o antenômero III com comprimento subigual ao IV, Mimasyngenes clarkei sp. nov. faz parte do grupo 2 (Clarke, 2007). Espécies de Mimasyngenes Breuning, 1950, pertencentes a esse grupo são: M. multisetosus Clarke, 2007, descrita da Bolívia, Tarija; M. ytu Galileo \& Martins, 1996, ocorrente no Brasil (Maranhão, Minas Gerais, São Paulo) e na Bolívia (Santa Cruz); M. icuapara Galileo \& Martins, 1996, que habita o Brasil (São Paulo) e a Argentina (Misiones), M. murutinga Martins \& Galileo, 2006 descrita do Equador (Manabi) e M. venezuelensis ocorrente na Venezuela (Caracas) e Bolívia (Santa Cruz). Com exceção de M. multisetosus e $M$. venezuelensis, as três outras têm espinhos longos e curvos nos lados do protórax.

M. clarkei distingue-se de M. ytu principalmente pelos élitros unicolores, os quais apresentam mancha umeral alaranjada em M. ytu. Distingue-se de $M$. murutinga pelo padrão de colorido dos élitros que é unicolor, quase sem pubescência e com pelos pretos; em M. murutinga é com pubescência branca, densa, que não recobre a base e manchas e com pelos brancos.

O padrão de colorido dos élitros é muito diferente em $M$. clarkei e M. murutinga: unicolor, quase sem pubescência e com pelos pretos em $M$. clarkei e com pubescência branca, densa, que não recobre a base e manchas e pelos brancos em $M$. murutinga.

M. clarkei é mais semelhante a M. icuapara, mas distingue-se: pelos élitros onde as fileiras de pontos não têm fileiras de pelos entremeadas; em $M$. icuapara as fileiras de pontos são entremeadas por fileiras de pelos. 


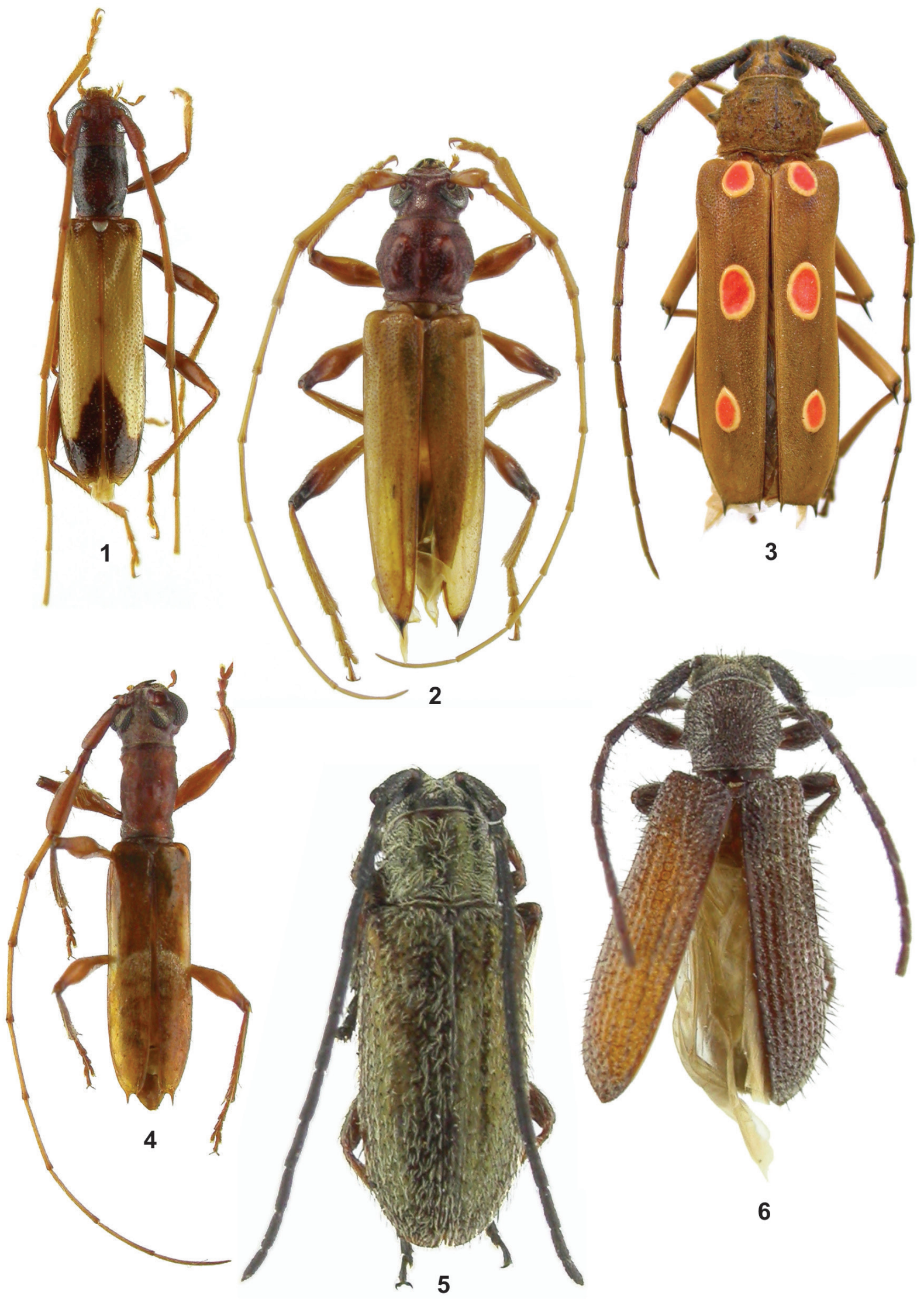

Figs 1-6. 1, Bomarion caudatum sp. nov., holótipo macho, comprimento $8,7 \mathrm{~mm} ; 2$, Nephalius levigatus sp. nov., holótipo macho, comprimento $16,8 \mathrm{~mm} ; 3$, Bothriopila pulcherrima sp. nov., holótipo fêmea, comprimento 33,1 mm; 4, Cycnidolon rufescens sp. nov., holótipo macho, comprimento 8,9 mm; 5, Cicatricallia cicatricosa sp. nov., holótipo macho, comprimento 5,0 mm; 6, Mimasyngenes clarkei sp. nov., holótipo fêmea, comprimento $6,6 \mathrm{~mm}$. 


\section{Mimasyngenes fonticulus sp. nov.}

(Fig. 7)

Etimologia. Latim, fonticulus $=$ diminutivo de fonte, alusivo à localidade tipo.

Tegumento corporal castanho-avermelhado, mais escuro no protórax. Setas pretas em todas as regiões corporais, menos na face ventral. Cabeça com pubescência esbranquiçada, esparsa. Lobos oculares superiores desenvolvidos, tão distantes entre si quanto o dobro da largura de um lobo. Antenas pretas atingem o ápice elitral. Escapo com pubescência esbranquiçada, esparsa e pelos longos em toda superfície. Antenômero III com comprimento subigual ao IV; antenômeros V-IX com comprimentos decrescentes.

Protórax apenas mais largo que longo. Lados do protórax com espinho curto, acuminado. Pronoto densamente pontuado e com pubescência esbranquiçada esparsa.

Élitros densamente pontuados em toda superfície, os pontos alinhados; pilosidade esbranquiçada e esparsa, mais concentrada nos lados do terço anterior. Extremidades elitrais arredondadas.

Pernas castanho-avermelhadas. Metatíbias gradualmente engrossadas para o ápice. Face ventral do corpo revestida por pubescência esbranquiçada.

Dimensões, em mm, holótipo macho. Comprimento total, 3,9; comprimento do protórax, 0,8 ; maior largura do protórax, 1,0; comprimento do élitro, 2,9; largura umeral, 1,2 .

Material-tipo. Holótipo macho, BRASIL, Piauí: Caracol (Parque Nacional da Serra das Confusões, Fonte dos Bois, 9'13'22,8'S, $43^{\circ} 29^{\prime} 39,1^{\prime \prime} W, 587$ m), 7-17.XII.2010, A. M. Silva Neto \& M. Xavier col., armadilha luminosa (UEFS).

Discussão. Pelo antenômero III tão longo quanto o IV pertence ao grupo 2 (Clarke, 2007). Pelo espinho lateral do protórax evidente e pelo élitro sem mancha de tegumento amarelado nos úmeros, Mimasyngenes fonticulus sp. nov. é discriminada com M. icuapara Galileo \& Martins, 1996 e M. murutinga Martins \& Galileo, 2006. Difere de M. icuapara pelo espinho lateral do protórax curto e reto e de $M$. murutinga pelas antenas pretas, pelos élitros sem pubescência densa e pelas margens dos élitros e dos fêmures com pelos pretos. Em M. icuapara o espinho lateral do protórax é longo com ápice voltado para trás e em $M$. murutinga, os antenômeros são avermelhados com ápices escurecidos, a maior parte dos élitros é coberta por pubescência densa e as margens dos élitros e dos fêmures possuem pelos brancos.

\section{Ibypeba gen. nov.}

Espécie-tipo. Ibypeba camiri sp. nov.

Etimologia. Tupi, ibypéba = planície; alusivo à forma da cabeça, larga e aplanada. Gênero feminino.

Corpo compacto. Cabeça larga. Fronte nitidamente mais larga que longa. Vértice aplanado. Olhos inteiros, com facetas moderadas. Lobos oculares superiores tão distantes entre si quanto mais do que o quíntuplo da largura de um lobo. Tubérculos anteníferos distantes entre si e não projetados. Antenas atingem as pontas dos élitros aproximadamente no ápice do antenômero IX (macho) ou do antenômero XI (fêmea). Escapo subcilíndrico (macho) ou bem esbelto (fêmea), com cerca de $2 / 3$ do comprimento do antenômero III. Antenômero III subigual em comprimento ao antenômero IV com franja interna de pelos com o dobro da largura do segmento. Antenômeros $\mathrm{V}$ a XI com comprimentos decrescentes. Protórax com largura (espinhos laterais inclusive) igual ao dobro do comprimento e constrição basal mais acentuada que a apical; lados com espinho situado no nível do terço basal. Pronoto sem tubérculos. Élitros largos, sem crista centro-basal, providos de pelos abundantes, evidentes em toda superfície; extremidades elitrais arredondadas em conjunto. Fêmures grossos, fusiformes, providos de pelos longos; nas fêmeas, com pedúnculo curto. Tíbias com pelos longos. Mesotíbias com entalhe próximo ao ápice. Cavidades mesocoxais abertas.

Discussão. Ibypeba gen. nov. assemelha-se a Mimasyngenes, mas difere pelo protórax muito largo, com espinho lateral situado próximo da base. Em Mimasyngenes o espinho lateral do protórax é situado no meio ou no início do terço posterior.

\section{Ibypeba camiri sp. nov. (Fig. 8)}

Etimologia. O nome específico refere-se à localidade-tipo.

Tegumento corporal e dos apêndices castanhoescuro a preto. Todo corpo revestido por pilosidade acinzentada, constituída por pelos relativamente longos. Cabeça larga. Olhos com granulações relativamente finas. Lobos oculares superiores com $c a$. oito fileiras de omatídios. Antenômeros III-X com anel basal de pilosidade acinzentada. Lados do protórax divergentes até os espinhos e estreitados em curva para a base. Espinho lateral do protórax situado no nível do terço basal. Pronoto sem tubérculos. Cada élitro com $c a$. oito fileiras longitudinais de pubescência, que se juntam no quarto apical.

Dimensões, em mm, holótipo macho/parátipo fêmea. Comprimento total, 4,5/4,9; comprimento do protórax, 0,9/0,9; maior largura do protórax, 1,6/1,9; comprimento do élitro, 3,2/3,6; largura umeral, 1,9/2,1.

Material-tipo. Holótipo macho, BOLÍVIA, Santa Cruz: “Cord. Prv., Rd to Itai, $83 \mathrm{~km} \mathrm{~N}$ Camiri" (19²0'S, 632ㄱ'W, 890 m), 17-18.XII.2011, Wappes, Lingafelter \& Woodley col. (MNKM). Parátipo fêmea, mesmos dados de holótipo (ACMS).

\section{Micratelodesmis gen. nov.}

Espécie-tipo, Micratelodesmis minor sp. nov. 
Etimologia. Grego, micro = pequeno; Atelodesmis, nome genérico de Desmiphorini. Gênero feminino.

Corpo esbelto. Fronte tão larga quanto longa. Vértice convexo. Olhos inteiros, com facetas moderadas. Antenas apenas ultrapassam os ápices dos élitros. Escapo levemente engrossado para o ápice, mais curto que o antenômero III, provido de pelos abundantes, densos, em toda a superfície. Antenômero III apenas mais longo que o IV. Antenômeros III e IV com franja de pelos longos, densos, em toda a superfície; no lado interno os pelos têm mais que o dobro da largura do artículo. Antenômeros V a XI com comprimentos ligeiramente decrescentes com pelos esparsos.

Protórax apenas mais largo que longo; constrições basal e apical da mesma largura; lados com gibosidade no nível do meio. Pronoto com três elevações discretas. Élitros com ligeira depressão no dorso; epipleuras verticais e extremidades arredondadas.

Fêmures sublineares. Mesotíbias sem entalhe, com franja de pelos longos nos dois terços apicais do lado externo.

Discussão. A semelhança de Micratelodesmis minor com espécies de Hemilophini é notável, especialmente pelas antenas com antenômeros III e IV densa e longamente pilosos. Entretanto, as garras tarsais simples e divaricadas colocam-na em Desmiphorini.

Assemelha-se a Atelodesmis Buquet, 1857, pelos antenômeros III e IV providos de pelos longos e densos. Difere das espécies de Atelodesmis pelas dimensões muito menores, pelos lobos oculares tão distantes entre si quanto à largura de um lobo; pelos lados do protórax com gibosidade no nível do meio; pela ligeira depressão no dorso dos élitros. Em Atelodesmis as dimensões são muito maiores (comprimento médio ca. 11,5 mm); lobos oculares superiores tão distantes entre si quanto o dobro da largura de um lobo; lados do protórax têm espículo, os élitros não têm depressão dorsal.

\section{Micratelodesmis minor sp. nov.}

(Fig. 9)

Etimologia. Latim, minor $=$ menos; alusivo às pequenas dimensões.

Cabeça castanho-escura; parte inferior da fronte com pubescência esbranquiçada; faixa amarelada, longitudinal inicia-se na frente dos tubérculos anteníferos e estende-se até o occipício. Lobos oculares superiores tão distantes entre si quanto a largura de um lobo. Antenas castanho-escuras atingem as extremidades dos élitros aproximadamente no ápice do antenômero IX.

Pronoto amarelado com uma faixa castanho-escura de cada lado da base ao ápice e ligeiramente divergentes. Lados do protórax e faixa centro-longitudinal do pronoto com pubescência amarelada.

Élitros inteiramente cobertos por pubescência amarelada e providos de pelos amarelados, abundantes, em toda superfície; dorso da parte anterior apenas deprimido.
Pernas e face ventral do corpo, preto-avermelhadas.

Dimensões, em mm, holótipo macho. Comprimento total, 6,4; comprimento do protórax, 1,2; maior largura do protórax, 1,3; comprimento do élitro, 4,6; largura umeral, 1,8.

Material-tipo. Holótipo macho, COSTA RICA, Cartago: Turrialba, sem data de coleta, E. A. Böttcher col., "Berlin C. 2" (USNM).

\section{HEMILOPHINI}

\section{Lycidola affinis sp. nov.}

(Fig. 10)

Etimologia. Latim, affinis = afim, pela semelhança com Lycidola batesi Aurivillius, 1923.

Cabeça com tegumento preto, menos nas proximidades do clípeo e nas genas, onde é pretoavermelhado; pequena mancha entre os tubérculos anteníferos, faixa longitudinal atrás dos olhos e genas revestidas por pubescência amarelada. Região superior da fronte algo projetada e deprimida longitudinalmente. Antenas pretas (quebradas na ponta do antenômero V). Antenômeros III-V com estreito anel basal de tegumento amarelado. Lados do protórax com gibosidade discreta no terço posterior. Pronoto preto com uma faixa de pubescência amarelada a cada lado. Élitros pretos; úmeros com pequena mancha amarelada (continuação das faixas do pronoto); no meio, faixa transversal branco-amarelada com bordas irregulares, que atinge a margem e a sutura. Fêmures amarelados com pontas pretas em, gradualmente, maior extensão dos proaos metafêmures. Tíbias e tarsos pretos. Prosterno e mesosterno avermelhados. Restante da face ventral do corpo preta.

Dimensões, em mm, holótipo macho. Comprimento total, 12,7; comprimento do protórax, 1,8; maior largura do protórax, 2,5; comprimento do élitro, 10,0; largura umeral, 3,0; maior largura dos élitros, 8,1.

Material-tipo. Holótipo macho, TRINIDAD E TOBAGO, Trinidad: St. Andrews Springhill Estate, Arima, II.1984, W. L. Murphy col. (USNM).

Discussão. Aurivillius (1923) mudou o status de Lycidola simulatrix var. (BATES, 1866:368) e denominou essa variedade como L. batesi, espécie que ocorre no Brasil (Amazonas e Pará). Lycidola affinis é muito semelhante a $L$. batesi e difere: fronte preta (indistintamente preto-avermelhada na parte inferior); região entre os lobos oculares superiores preta; protórax mais estreito (comprimento1,8 x largura 2,5); mancha amarelada na base dos élitros pequena, somente nos úmeros; faixa transversal dos élitros com a borda anterior mais curva e atinge a margem e a sutura. Em L. batesi: fronte e genas com tegumento avermelhado; região entre os lobos oculares superiores avermelhada; protórax mais largo (comprimento 1,9-2,0 x largura 2,8- 


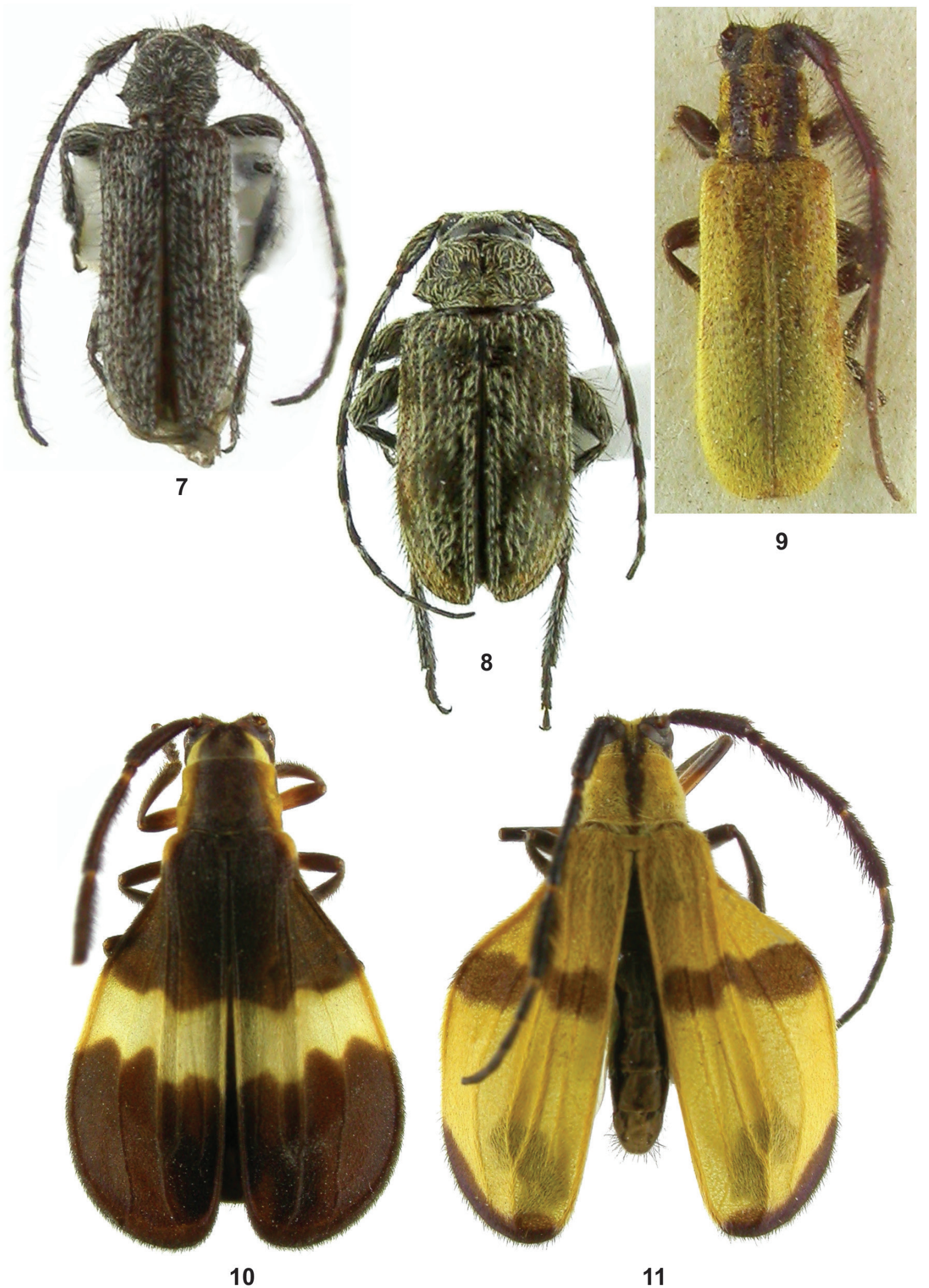

Figs 7-11. 7, Mimasyngenes fonticulus sp. nov., holótipo macho, comprimento 3,9 mm; 8, Ibypeba camiri sp. nov., holótipo macho, comprimento 4,5 mm; 9, Micratelodesmis minor sp. nov., holótipo macho, comprimento 6,4 mm; 10, Lycidola affinis sp. nov., holótipo macho, comprimento $12,7 \mathrm{~mm}$; 11, Lycidola beltii Bates, 1872, macho, comprimento 12,4 mm. 
3,0); mancha amarelada na base dos élitros variável de restrita aos úmeros até uma faixa curta; faixa transversal amarelada dos élitros não cobre a sutura e é sub-reta na borda anterior.

\section{Lycidola beltii Bates, 1872}

(Fig. 11)

Lycidola beltii BATEs, 1872:228.

Hemilophus belti; Gemminger \& Harold, 1873:3208 (cat.). Lycidola belti; CHEMSAK et al., 1992:160 (cat.).

É provável que Lycidola beltii, originalmente descrita da Nicarágua, seja uma espécie altamente variável no colorido. $\mathrm{O}$ exemplar que estudamos procedente da Costa Rica tem élitros inteiramente amarelados com apenas duas faixas pretas estreitas: uma no terço anterior e uma que ocupa os ápices em pequena extensão (Fig. 11). O pronoto, com estreita faixa preta centro-longitudinal, concorda com a ilustração do holótipo (BATES, 1881:224, est. 15, fig, 1).

Material examinado. COSTA RICA, San José: Zurqui de Moravia $\left(10^{\circ} 03^{\prime} \mathrm{N}, 84^{\circ} 01^{\prime} \mathrm{W}, 1600 \mathrm{~m}\right)$, macho, VI.1990, P. Hanson col., armadilha de Malaise (USNM).

\section{Alampyris fuscus Martins \& Galileo, 2008}

Alampyris fuscus Martins \& Galileo, 2008:550, fig. 3.

A espécie foi originalmente descrita da Costa Rica: Guanacaste e ora assinala-se para o Panamá.

Material examinado. PANAMÁ, Canal Zone: Gamboa (5 mi $\left.\mathrm{N}, 09^{\circ} 10^{\prime} 00^{\prime \prime N}, 79^{\circ} 45^{\prime} 00^{\prime \prime} \mathrm{W}, 100 \mathrm{~m}\right)$, macho, 23-24.X.1975, “canopy fogging experiment in Luehea see mannii, Pyrethrin fog, sample 8A, 24.X.1975” (USNM).

Agradecimentos. A James Wappes (ACMS, USNM), Freddy Rubem Bravo Quijano e Francisco Eriberto (UEFS) pela remessa de material para estudo; a Antonio Santos Silva (MZSP) pela execução das fotografias.

\section{REFERÊNCIAS BIBLIOGRÁFICAS}

Aurivillius, C. 1923. Neue oder wenig bekannte Coleoptera Longicornia 19. Arkiv för Zoology 15(25):437-479.

Bates, H. W. 1866. Contributions to an insect fauna of the Amazon Valey. Coleoptera: Longicornes. Annals and Magazine of Natural History (3)17:367-373.

1872. On the longicorn Coleoptera of Chontales, Nicaragua. Transactions of the Entomological Society of London 1872:163-238.

1881. Biologia Centrali-Americana. Insecta, Coleoptera, Longicornes, London, British Museum of Natural History, v. 5, p. $153-224$.

Chemsak, J. A.; Linsley, E. G. \& Noguera, F. A. 1992. Listados Faunísticos de México II. Los Cerambycidae y Disteniidae de Norteamérica, Centroamérica y las Indias Occidentales. México, Universidad Nacional Autónoma de México, Instituto de Biologia. 204 p.

Clarke, R. O. S. 2007. Synopsis of the Bolivian species of Mimasyngenes Breuning, 1950 (Coleoptera, Cerambycidae, Desmiphorini) with two new species. Papéis Avulsos de Zoologia 47(26):359-368.

Gemminger, M. \& Harold, E. von. 1873. Catalogus Coleopterorum hucusque descriptorum synonymicus et systematicus. Monachii. v.10, p. 2989-3232.

Martins, U. R. 2005. Cerambycidae sul-americanos (Coleoptera). Curitiba, Sociedade Brasileira de Entomologia, v.7, II+394 p.

Martins, U. R. \& Galileo, M. H. M. 2007. Tribo Ibidionini, Subtribo Ibidionina. p. 177-330. In: Cerambycidae sul-americanos (Coleoptera). Curitiba, Sociedade Brasileira de Entomologia, v. 9 , II+349 p.

. Novos táxons e novo registro em Hemilophini (Coleoptera: Cerambycidae: Lamiinae). Revista Brasileira de Zoologia 25(3):547-554. 